\title{
Functional outcome of Schatzker type V and VI tibial plateau fractures managed with open reduction internal fixation using dual plates
}

\section{Saranjeet Singh Jagdev, Subodh Kumar Pathak*, Abhijeet Salunke, Pritam Maheshwari, Prahlad Ughareja, Shaurya Shah}

Department of Orthopedics, Pramukhswami Medical College, Karamsad, Gujarat, India

Received: 28 June 2017

Accepted: 14 July 2017

\section{*Correspondence:}

Dr. Subodh Kumar Pathak,

E-mail: drsubodh08@gmail.com

Copyright: () the author(s), publisher and licensee Medip Academy. This is an open-access article distributed under the terms of the Creative Commons Attribution Non-Commercial License, which permits unrestricted non-commercial use, distribution, and reproduction in any medium, provided the original work is properly cited.

\section{ABSTRACT}

Background: Complex tibial plateau fractures remain a challenge to even the most experienced surgeons. These injuries usually affect the young population in their productive years thereby causing socioeconomic impact. We performed a retrospective study to evaluate the functional outcome of of Schatzker type V and VI managed through open reduction and internal fixation.

Methods: 26 patients with Schatzker type V and type VI tibial plateau fractures treated with open reduction and internal fixation using plates were included in the study. Three patients were lost to follow up, 23 patients were evaluated in the final analysis. The preoperative, intraoperative data was noted from the indoor files.The final evaluation was done using Oxford knee score and VAS score.

Results: There were nine Schatzker type V fractures and 14 patients with Schatzker type VI fractures. The mean duration of follow-up was 68.32 months ranging from 41 months to 126 months. The mean Oxford knee score was 39.78. Patients with Schatzker type VI had mean OKS of 37.7.The mean MPTA and mean PPTA were 88.75 degrees and 7.35 degrees respectively. Average VAS Score was 2.8 ranging from 1 to 3.9. All patients returned to their preinjury level of activity and employment. There were no patients of deep infection.

Conclusions: We conclude that open reduction and internal fixation of high-energy tibial plateau fractures gives excellent to good functional outcome with minimal soft tissue complications. The complications can be minimized with proper patient selection and soft tissue dissection.

Keywords: Tibial plateau fractures, Oxford knee score, Schatzker type V, Schatzker type VI, Soft tissue injury

\section{INTRODUCTION}

Surgical treatment of high-energy tibial plateau fractures remains a challenge due to problems encountered which include wound complications, infection, varus collapse, knee stiffness, and articular malreductions. ${ }^{1-3}$ High energy tibial fractures usually affect the younger age group in productive life years and have significant socioeconomic impact due to late recovery time and subsequent requirement of early total knee replacement in some complicated cases. ${ }^{4}$ Schatzker classified fractures of tibial plateau radiologically from type I to VI. ${ }^{5}$ Schatzker type V and VI fractures are high-energy fractures often accompanied by other injuries and complications. The complexity of the fracture pattern and the associated soft tissue disruption of these types of fractures contribute to high rate of failure and unsatisfactory results which follow both operative and non-operative management. ${ }^{6,7}$ Several fixation methods could be used for tibial plateau fractures including unilateral fixation with a single plate, dual-plate, a hybrid external fixator or a less invasive stabilizing system. ${ }^{8-10}$ There is a considerable debate regarding the best method for treating proximal tibia fractures and there is no clear consensus on which leads 
to the best outcomes. The aim of current study was to review the functional outcome and complications in cases of Schatzker types V and VI tibial plateau fractures treated by open reduction and internal fixation with dual plates.

\section{METHODS}

A retrospective study was done in tertiary care center. This study was examined and approved by the Human research ethics committee. The inpatient records of Schatzker type V and VI fracture patients from Jan 2008 to June 2012 were traced from the medical records department. Patients between 20-75 years of age, unilateral involvement, were included. Patients with compartment syndrome, pathological fracture, any knee deformity, surgery on ipsilateral knee were excluded. Total of 26 patients were included in the study. 3 patients were lost to follow up 23 patients were included in the retrospective analysis after applying the inclusion/exclusion criteria. The indoor records were examined and preoperative data were collected.

The operative notes were reviewed and duration of the surgery, time since injury to the surgery, the type of anesthesia, and blood loss were noted. All the patients had undergone open reduction through an anterolateral approach for lateral plate, and medial or posteromedial approach for the second plate. Surgeries were performed under fluoroscopic control to aid and assess the reduction. Bone grafts were used in depressed and comminuted fractures. The source of bone graft was iliac crest.

All the patients who were selected for the study were called for follow-up. The patients were asked to bring the follow-up outpatient records which were retained by the patients during the treatment course. At final follow up radiographs of the knee and leg were obtained in the anteroposterior and lateral planes to assess the articular congruity and radiological union. Radiological outcome evaluation was assessed by parameters i.e. medial proximal tibial angle (MPTA), posterior proximal tibial angle (PPTA). The patients were also questioned regarding functional recovery and their responses noted. The Functional results were analyzed using the Oxford knee score criteria. The patients were asked twelve questions about the degree of pain in knee, any difficulty in toilet activities, ability to perform household activities, climbing up or down stairs, ability to kneel, night pains, any limp in the operated limb, ability to kneel down and stand again, and any discomfort in washing and drying oneself due to knee and various other questions mentioned in Oxford knee score. ${ }^{11}$ The patients were graded as poor (0 to 19$)$, moderate (20 to 29 ), good (30 to 39 ), and excellent (40 to 48). The patients who had scored more than 40 were considered as cases with satisfactory functional outcome and minimal disability.
Pain was assessed using the visual analogue scale (VAS) at every follow-up.

\section{Statistical analysis}

STATA 14.0 was used for data variation analysis. The mean and range for all continuous variables were obtained. The $\mathrm{p}$ value for statistical significance was set at $\mathrm{p}<0.05$.

\section{RESULTS}

Out of 23 patients included in final analysis, 9 (39.13\%) patients were Schatzker type V fracture while 14 $(60.86 \%)$ were classified as having Schatzker VI tibial plateau fractures.

In this study eighteen patients were men and five patients were women. All the injuries were a result of Road traffic accidents. The mean age of the patients was 38.7 years ranging from 22 to 68 years. The mean duration of hospital stay was 7 days ranging from 4 to 17 days. The mean duration of follow up was 68.32 months (range 41 to 126 months).

There was involvement of left side in 6 cases and 17 on the right side and none of the cases had bilateral tibial plateau fracture. Patients with extensive swelling were managed with calcaneal skeletal traction with elevation on Bohler splint and ice pack application until swelling subsided. Two patients underwent knee spanning external fixator followed by definitive fixation (Figure no 1). All patients in this study underwent surgery at a mean interval of 4 days (range 8 hours to 13 days).In our study the mean time interval between admission and definitive surgery was 4 days (range 8 hours to 13 days. The mean duration of the surgery was $2 \mathrm{hr} 12 \mathrm{~min}$ (range: $70 \mathrm{~min}$ to $3 \mathrm{hrs} 10 \mathrm{~min}$ ). The mean blood loss was $280 \mathrm{ml}$ (range: $200 \mathrm{ml}$ to $380 \mathrm{ml}$ ).

Bone grafting was done in 4 cases of type VI fractures and in one case of type $\mathrm{V}$ fracture

There were four associated fractures in 3 patients. One patient had fracture of multiple metatarsals in ipsilateral foot, and ipsilateral Colles' fracture, one patient had open forearm fracture and one patient had an contralateral elbow fracture dislocation.

Mean time for radiological bony union was $16.31 \pm 2.15$ weeks with $68.2 \%$ cases having union time between 13 19 weeks. Mean time of full weight bearing was 21.5weeks.

In this study, two patients (8.69\%) developed postoperative superficial wound infection which was treated with intravenous antibiotics. Out of these two patients, one patient had open grade 3 fracture and the other patient had diabetes mellitus (Table 1). 
Table 1: Functional outcome.

\begin{tabular}{|ll|}
\hline Mean Oxford knee score & $\mathbf{3 9 . 7 8}$ \\
\hline Mean flexion of knee & 123.4 degrees \\
\hline Mean VAS score & 2.8 \\
\hline $\begin{array}{l}\text { Mean time for radiological } \\
\text { union }\end{array}$ & 16.31 weeks \\
\hline Complication rate & $\begin{array}{l}8.69 \% \text { superficial } \\
\text { infection, no deep } \\
\text { infection }\end{array}$ \\
\hline
\end{tabular}

There was loss of articular reduction manifested by articular depression $(>4 \mathrm{~mm})$ in two patients. Three patients had articular step of less than $2 \mathrm{~mm}$. At the final follow-up, the mean medial proximal tibial angle (MPTA) was $88.75^{\circ}$ (range: $81^{\circ}-92^{\circ}$ ), the mean proximal posterior tibial angle (PPTA) was $7.35^{\circ}$ (range: $4^{\circ}-13^{\circ}$ ). The angles had not shown statistically significant difference between the operated knee and the contralateral uninjured knee.

Table 2: Oxford knee score.

\begin{tabular}{|lll|}
\hline $\begin{array}{l}\text { Oxford knee } \\
\text { score }\end{array}$ & $\begin{array}{l}\text { Number of } \\
\text { patients }\end{array}$ & $\begin{array}{l}\text { Percentage } \\
(\%)\end{array}$ \\
\hline $\mathbf{0 - 1 9}$ & 0 & 0 \\
\hline $\mathbf{2 0 - 2 9}$ & 2 & 8.69 \\
\hline $\mathbf{3 0 - 3 9}$ & 6 & 26.08 \\
\hline $\mathbf{4 0 - 4 8}$ & 15 & 65.21 \\
\hline Total & 23 & 100 \\
\hline
\end{tabular}

The mean flexion at final follow up was 123.4 Degrees \pm 5.60 (Range 110 to 135 ). Five patients had extension lag less than 10 degrees.
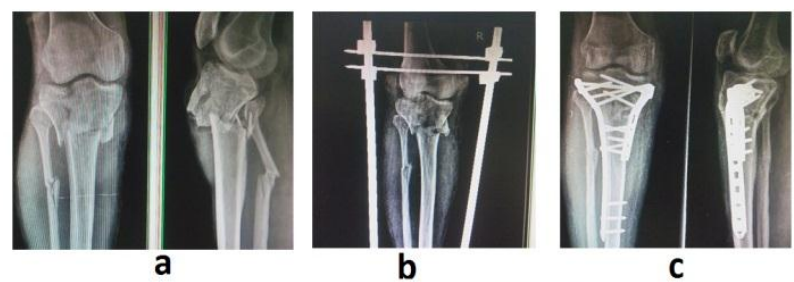

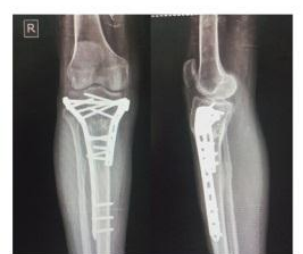

d

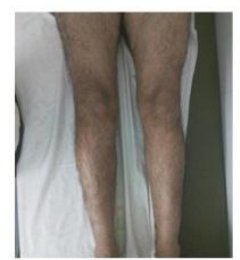

e

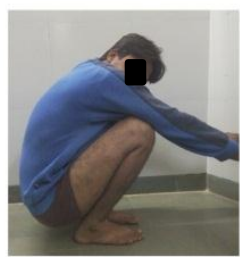

$f$
Figure 1: Patient A with Schatzker type VI fracture. a: Pre-operative radiograph b: External fixator c: 4 months follow up radiograph d: 9 month follow up radiograph e: Clinical picture of Bilateral knee f: Functional outcome (Squatting)

At the final follow up the Oxford knee score (OKS) was between 40 to 48 in 15 patients and between 20 to 29 in 2 patients. The mean Oxford knee score was 39.78. The mean OKS score in type $\mathrm{V}$ was 41.65 and in type VI was 37.7 (Table 2).

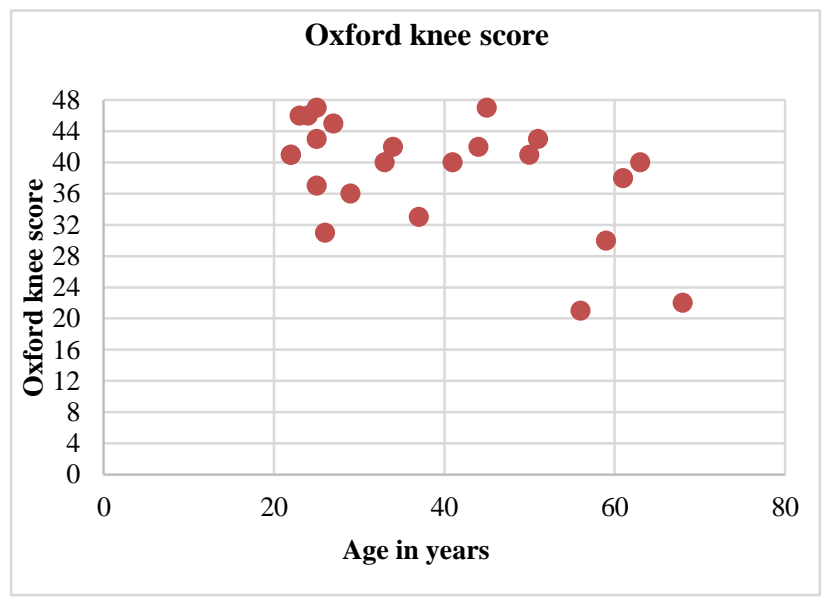

Figure 2: Correlation between OKS and age in years.

The oxford knee score was excellent in $65.21 \%$, good in $26.08 \%$ and no patients had poor results (Figure 1). There was a negative correlation between age of the patient and the oxford knee score. Older patients scored lower score, but this finding was not statistically significant $(\mathrm{p}=0.451)$ (Figure 2).The mean VAS score was 2.8 ranging from 1 to 3.9 .

\section{DISCUSSION}

High energy trauma and associated soft tissue insult increases the chances of complications in type $\mathrm{V}$ and type VI fractures. Surgery further traumatizes the soft tissue envelope and acts as a second hit to the soft tissues if not done at appropriate time. Therefore, optimal decision for the management of complex bicondylar tibial plateau is most important.

Open reduction and internal fixation of high-energy tibial plateau fractures remains one of the most acceptable methods of fixation as it allows direct visualization and reduction of the fracture. ${ }^{12}$ Surgery using single midline incision not only puts the soft tissue on excessive stretch but also the problem of reaching the posteromedial fragment through a single incision causes wide periosteal stripping and extensive muscle dissection and may hamper reduction as well. ${ }^{13}$ Dual incisions are better than single incision. ${ }^{14}$ The introduction of locking plates and minimally invasive approach has decreased the complication rate by many folds but still the optimal management of these fractures remains controversial. ${ }^{15} \mathrm{~A}$ recent study suggested that the use of external fixator in treatment of tibial plateau fractures lead to fewer complications and early mobilization as compared to internal fixation. ${ }^{16}$ However, an earlier study reported that the use of a hybrid external fixator also causes infection around the pin site and may lead to septic arthritis of knee joint. $^{17}$ 
Whereas majority of the studies use radiological parameters in operated tibial plateau fractures for functional outcome, the current trend is to use patientspecific tools to measure functional outcomes. ${ }^{18}$ In our study Oxford knee score was used for functional evaluation of the patients. It is a patient-specific tool to assess the patient's perspective regarding the outcome of the surgery. It is a reliable, valid, simple, short, and practical questionnaire. ${ }^{19}$

In our study we followed a staged protocol, stabilizing the patient using advanced trauma management guidelines. If there was extensive soft tissue injury, as indicated by soft tissue edema, fracture blisters, definitive fixation was delayed. The limb was elevated on Bohler splint and calcaneal pin traction was applied with $5 \mathrm{~kg}$ of weight. In two cases temporary stabilization with external fixator was done. Once the soft tissues recovered, as evidenced by resolution of the edema and the fracture blisters and appearance of skin wrinkles, the patient was taken up for definitive surgery.

In our study the mean time interval between admission and definitive surgery was 4 days (range 8 hours to 13 days) which is comparable with various studies. In a study by Yao et al the time interval ranged from 7 to 14 days while Pun et al in their study reported time interval of 12 hours to 21 days (mean time 5.11 days). ${ }^{20,21}$

In our study, mean time for bony union was 16.31 weeks ranging from 13 to 19 weeks. In study by Zhang et al., the mean period for union was 14.1 weeks in double buttress plate group. ${ }^{22}$ Prasad et al found that union occurred in 8-22 weeks with a mean of 14 weeks. ${ }^{23}$

In our study the Oxford knee score was excellent in $65.21 \%$ patients and poor in none. In a study of 65 cases of type V and type VI fractures by Khatri et al, 54 patients $(83 \%)$ had excellent result. ${ }^{24}$ A study by Prasad et al. has observed excellent oxford knee score in $40 \%$ of their patients treated with dual incision and dual plate. ${ }^{23}$

The most dreadful complication associated with the management of tibial plateau fractures is infection. The incidence of infection can be reduced by timing of surgery and proper soft tissue handling. ${ }^{25}$ In 2006, a multicenter, prospective, randomized control trial by Canadian Orthopedic Trauma Society reported an overall infection rate of $18 \%$ in bicondylar tibial plateau fractures treated with open reduction and internal fixation ${ }^{3}$. In a study by Khatri et al, superficial wound infection was seen in $9.2 \%$ patients while deep infection was seen in $4.6 \%$ of patients. ${ }^{24}$ Barei et al, had reported superficial infection in $5.4 \%$ patients and deep wound infections $3.6 \%$ patients. ${ }^{14}$ Nabil et al, had reported infection in five of their 117 cases (4.2\%), which were successfully treated with debridement and intravenous antibiotics. ${ }^{4}$ In our series the incidence of superficial infection is $8.69 \%$ and there was no deep infection. We believe that staged intervention and waiting for the skin swelling to subside and soft tissues to heal can reduce the complication rate and thereby improve the patient's clinical outcome.

\section{CONCLUSION}

The planning of the patients with type $\mathrm{V}$ and type VI Schatzker fractures starts as soon as the patients enters the emergency trauma center. Careful planning and staged protocol improves the clinical, functional and radiological outcomes. The status of soft tissue at the time of injury and the handling of soft tissue during surgery has a significant impact on the final outcome. The aggressive physiotherapy with knee mobilization and gait training prevents knee stiffness and dictates the final functional outcome and patient satisfaction.

Funding: No funding sources

Conflict of interest: None declared

Ethical approval: The study was approved by the institutional ethics committee

\section{REFERENCES}

1. Young MJ, Barrack RL. Complications of internal fixation of tibial plateau fractures. Orthop Rev. 1994;23:149-54.

2. Mallik AR, Covall DJ, Whitelaw GP. Internal versus external fixation of bicondylar tibial plateau fractures. Orthop Rev. 1992;21:1433-6.

3. Mckee MD, Pirani SP, Stephen DJ. The Canadian Orthopedic Trauma Society, Open reduction and internal fixation compared with circular fixator application for bicondylar tibial plateau fractures. Results of a multicenter, prospective, randomized clinical trial. J Bone Joint Surg Am. 2006;88:261323

4. Ebraheim NA, Sabry FF, Haman SP. Open reduction and internal fixation of 117 tibial plateau fractures. Orthopedics. 2004;27(12):1281-7.

5. Schatzker J. Anterior approach to the knee with osteotomy of the tibial tubercle for bicondylar tibial fractures. J Bone Joint Surg Am. 1988;70:1575-6.

6. Blokker CP, Rorabeck CH, Bourne RB. Tibial plateau fractures: an analysis of the results of treatment in 60 patients. Clin Orthop Relat Res. 1984;182:193-9.

7. Ali AM, Burton M, Hashmi M, Saleh M. Outcome of Complex Fractures of the Tibial Plateau Treated with a Beam-Loading Ring Fixation System. J Bone Joint Surg. 2003;85(5):691-9.

8. Berkson EM, Virkus WW. High-energy tibial plateau fractures. J Am Acad Orthop Surg. 2006;14:20-31.

9. Insall JN, Dorr LD, Scott RD, Scott WN. Rationale of the Knee Society clinical rating system. Clin Orthop Relat Res. 1989;248:13-4.

10. Jiang R, Luo CF, Wang MC, Yang TY, Zeng BF. A comparative study of Less Invasive Stabilization System (LISS) fixation and two-incision double 
plating for the treatment of bicondylar tibial plateau fractures. Knee. 2008;15:139-43.

11. Murray D, Fitzpatrick R, Rogers K, Pandit H, Beard $\mathrm{D}$, Carr A, et al. The use of the Oxford hip and knee scores. J Bone Joint Surg Br. 2007;89:1010-4.

12. Lachiewicz PF, Funcik T. Factors influencing the results of open reduction and internal fixation of tibial plateau fractures. Clin Orthop Relat Res. 1990;259:210-5.

13. Moore TM, Patzakis MJ, Harvey JP. Tibial plateau fractures: Definition, demographics, treatment rationale, and long term results of closed traction management or operative reduction. J Orthop Trauma. 1987;1:97-119.

14. Barei DP, Nork SE, Mills WJ, Coles CP, Henley MB, Benirschke SK. Functional outcomes of severe bicondylar tibial plateau fractures treated with dual incisions and medial and lateral plates. J Bone Joint Surg. 2006;88(8):1713-21.

15. Stannard JP, Wilson TC, Volgas DA. The less invasive stabilization system in the treatment of complex fractures of the tibial plateau: short-term results. J Orthop Trauma. 2004;18:552-8.

16. Kumar A, Whittle AP. Treatment of complex (Schatzker Type VI) fractures of the tibial plateau with circular wire external fixation: retrospective case review. J Orthop Trauma. 2000;14:339-44.

17. Hutson JJ, Jr, Zych GA. Infections in periarticular fractures of the lower extremity treated with tensioned wire hybrid fixators. J Orthop Trauma. 1998;12:214-8.

18. Williams DP, Blakey CM, Hadfield SG, Murray DW, Price AJ, Field RE. Long-term trends in the Oxford knee score following total knee replacement. J Bone Joint Surg. 2013;95(1):45-51.

19. Hawker GA, Melfi CA, Paul JE, Green R, Bombardier C. Comparison of a generic (SF-36) and a disease specific (WOMAC)(Western Ontario and McMaster Universities Osteoarthritis Index) instrument in the measurement of outcomes after knee replacement surgery. J Rheumatol. 1995;22(6):1193-6.

20. Yao Y, Lv H, Zan J, Li J, Zhu N, Jing J. Functional outcomes of bicondylar tibial plateau fractures treated with dual buttress plates and risk factors: a case series. Injury. 2014;45(12):1980-4.

21. Pun TB, Krishnamoorthy VP, Poonnoose PM, Oommen AT, Korula RJ. Outcome of Schatzker type $\mathrm{V}$ and $\mathrm{VI}$ tibial plateau fractures. Indian $\mathrm{J}$ Orthop. 2014;48(1):35-41.

22. Zhang Y, Fan D, Ma B, Sun S. Treatment of complicated tibial plateau fractures with dual plating via a 2-incision technique. Orthopedics. 2012;35(3):359-64.

23. Prasad GT, Kumar TS, Kumar RK, Murthy GK, Sundaram N. Functional outcome of Schatzker type $\mathrm{V}$ and VI tibial plateau fractures treated with dual plates. Indian J Orthop. 2013;47(2):188-94.

24. Khatri K, Lakhotia D, Sharma V, Kumar KGN, Sharma G, Farooque K. Functional Evaluation in High Energy (Schatzker Type V and Type VI) Tibial Plateau Fractures Treated by Open Reduction and Internal Fixation. Int Scholarly Res Notices. 2014(2014):589538.

25. Cole PA, Zlowodzki M, Kregor PJ. Treatment of proximal tibia fractures using the less invasive stabilization system: surgical experience and early clinical results in 77 fractures. J Orthop Trauma. 2004;18(8):528-35.

Cite this article as: Jagdev SS, Pathak SK, Salunke A, Maheshwari P, Ughareja P, Shah S. Functional outcome of Schatzker type V and VI tibial plateau fractures managed with open reduction internal fixation using dual plates. Int J Res Orthop 2017;3:961-5 